\title{
Review
}

\section{Genetic Neonatal-Onset Epilepsies and Developmental/Epileptic Encephalopathies with Movement Disorders: A Systematic Review}

\author{
Carlotta Spagnoli $^{1, *(D)}$, Carlo Fusco ${ }^{1}\left(\mathbb{D}\right.$, Antonio Percesepe $^{2}\left(\mathbb{D}\right.$, Vincenzo Leuzzi ${ }^{3}$ and Francesco Pisani ${ }^{4}$ \\ 1 Child Neurology Unit, AUSL-IRCCS di Reggio Emilia, 42122 Reggio Emilia, Italy; carlo.fusco@ausl.re.it \\ 2 Medical Genetics, Department of Clinical and Experimental Medicine, University Hospital of Parma, \\ 43126 Parma, Italy; antonio.percesepe@unipr.it \\ 3 Department of Paediatrics, Child Neurology and Psychiatry, Sapienza University of Rome, Via dei Sabelli 108, \\ 00185 Rome, Italy; vincenzo.leuzzi@uniroma1.it \\ 4 Child Neuropsychiatry Unit, University Hospital of Parma, 43126 Parma, Italy; francesco.pisani@unipr.it \\ * Correspondence: carlotta.spagnoli@ausl.re.it
}

check for

updates

Citation: Spagnoli, C.; Fusco, C.; Percesepe, A.; Leuzzi, V.; Pisani, F. Genetic Neonatal-Onset Epilepsies and Developmental/Epileptic Encephalopathies with Movement Disorders: A Systematic Review. Int. J. Mol. Sci. 2021, 22, 4202. https:// doi.org/10.3390/ijms22084202

Academic Editor: Stanislaw Jerzy Czuczwar

Received: 9 March 2021

Accepted: 14 April 2021

Published: 18 April 2021

Publisher's Note: MDPI stays neutral with regard to jurisdictional claims in published maps and institutional affiliations.

Copyright: (c) 2021 by the authors. Licensee MDPI, Basel, Switzerland. This article is an open access article distributed under the terms and conditions of the Creative Commons Attribution (CC BY) license (https:// creativecommons.org/licenses/by/ $4.0 /)$.

\begin{abstract}
Despite expanding next generation sequencing technologies and increasing clinical interest into complex neurologic phenotypes associating epilepsies and developmental/epileptic encephalopathies (DE/EE) with movement disorders (MD), these monogenic conditions have been less extensively investigated in the neonatal period compared to infancy. We reviewed the medical literature in the study period 2000-2020 to report on monogenic conditions characterized by neonatal onset epilepsy and/or DE/EE and development of an MD, and described their electroclinical, genetic and neuroimaging spectra. In accordance with a PRISMA statement, we created a data collection sheet and a protocol specifying inclusion and exclusion criteria. A total of 28 different genes (from 49 papers) leading to neonatal-onset DE/EE with multiple seizure types, mainly featuring tonic and myoclonic, but also focal motor seizures and a hyperkinetic MD in $89 \%$ of conditions, with neonatal onset in $22 \%$, were identified. Neonatal seizure semiology, or MD age of onset, were not always available. The rate of hypokinetic MD was low, and was described from the neonatal period only, with WW domain containing oxidoreductase (WWOX) pathogenic variants. The outcome is characterized by high rates of associated neurodevelopmental disorders and microcephaly. Brain MRI findings are either normal or nonspecific in most conditions, but serial imaging can be necessary in order to detect progressive abnormalities. We found high genetic heterogeneity and low numbers of described patients. Neurological phenotypes are complex, reflecting the involvement of genes necessary for early brain development. Future studies should focus on accurate neonatal epileptic phenotyping, and detailed description of semiology and time-course, of the associated MD, especially for the rarest conditions.
\end{abstract}

Keywords: newborn; epilepsy; epileptic encephalopathy; developmental encephalopathy; movement disorder; monogenic

\section{Introduction}

Neonatal-onset epilepsies follow a different time course and evolution from acquired symptomatic neonatal seizures [1]. Acute symptomatic neonatal seizures are sustained by acute, acquired injury to the central nervous system, notably hypoxic-ischemic encephalopathy, intraventricular hemorrhage, perinatal ischemic stroke or, less frequently, infections or transient metabolic derangement. They typically tend to cease spontaneously after the first days of life, but can be followed by the occurrence of recurrent spontaneous seizures (epilepsy) later in life in a substantial proportion of patients. On the contrary, neonatal seizures caused by structural (genetically driven) or nonstructural inborn metabolic or genetic etiologies are self-sustained phenomena, which must be considered as early onset epilepsies [2]. 
With the advent of broad sequencing methods, improved diagnostic yield has been reached, and these are now estimated to represent $10 \%-15 \%$ of all neonatal seizures [3].

In the last few years, our awareness of the association between genetically determined epilepsies, or developmental/epileptic encephalopathies (DE/EE) with movement disorders (MD), has increased; in some cases, delineating specific phenotypes [4-6]. While this association in the neonatal period is most frequently caused by neurometabolic disorders [7], nonmetabolic monogenic conditions also have to be taken into account. However, the occurrence of both these features during the neonatal period is still under investigated, and literature data are limited.

Therefore, we undertook a systematic literature review to describe the phenotypic and genotypic spectra of MD in genetic neonatal-onset epilepsies and DE/EE.

\section{Methods}

\subsection{Protocol}

A systematic literature review, according to a PRISMA statement [8], was performed. A protocol specifying inclusion/exclusion criteria, outcome measures, and analytical methods was created.

\subsubsection{Eligibility Criteria}

Inclusion criteria: studies conducted on humans focusing on genetic epilepsies and/or DE/EE (as defined by ILAE [9]) with neonatal-onset cases with onset of MD(s), as classified in [10] at any age; proven monogenic etiology, demonstrated by detecting definitely or likely pathogenic variants according to ACMG criteria [11] (by single gene testing, targeted nextgeneration sequencing panels or whole exome sequencing); written in English; published between 1 January 2000 and 31 December 2020. Ages at MD onset were classified as: neonatal/early infantile (birth-4 months), infantile (5-12 months), toddler (1-3 years), early childhood (3-8 years), late childhood (9-11 years), adolescence (12-18 years), and adulthood ( $\geq 18$ years).

Exclusion criteria: Reviews, authors' replies and commentaries, book chapters, nonEnglish language papers, animal experiments, articles on structural, autoimmune or neurometabolic etiologies; molecular diagnosis unavailable.

\subsubsection{Information Sources}

PubMed and Scopus databases. Reference lists were reviewed in order to collect additional papers.

\subsubsection{Search}

Our search terms were: (neonatal) AND (epileptic encephalopathy) OR (epilepsy) AND (movement disorder).

\subsubsection{Study Selection}

Results were reviewed by title, abstract and by full-text review.

\subsubsection{Data Items}

Data collection sheet is available as supplementary material.

The quality of evidence was rated according to [12] (Table S1).

\section{Results}

Articles' selection flow-chart is detailed in Figure 1. 


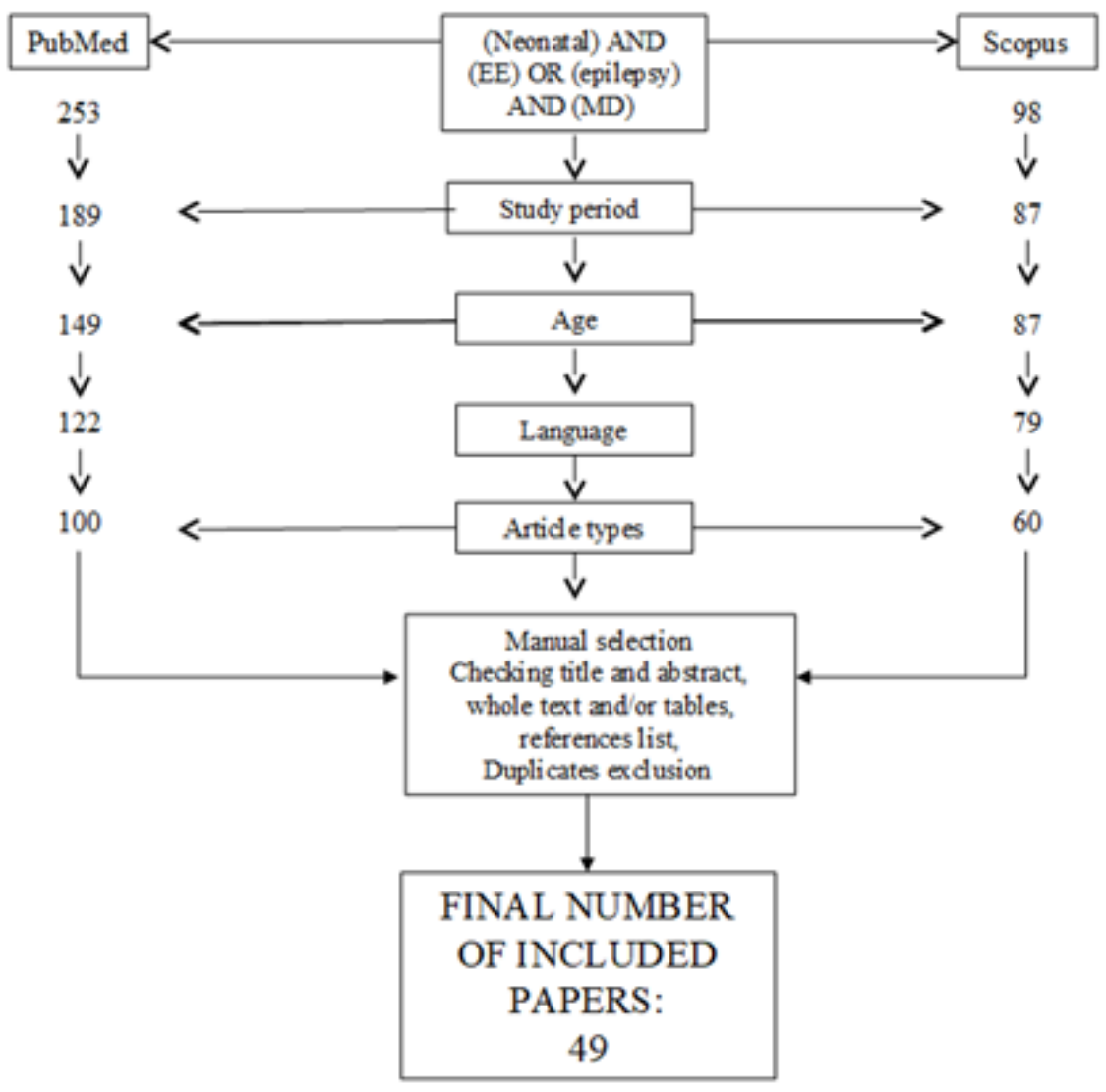

Figure 1. Articles selection flow-chart.

A total of 49 studies on 27 genes satisfied the inclusion criteria. We identified more than one paper for eight genes: ATP1A3 (one case series [13], one case report [14]); GNAO1 (four original articles [15-18], one case report [19]); KCNQ2 (two original articles [20,21], one case series [22], two case reports [23,24]); SCN8A (three original articles [6,25,26], two case reports $[27,28]$ ); SLC13A5 (two original articles [29,30]); STXBP1 (two original articles [31,32], one case series [33], one case report [34]); SCN2A (three original articles [35-37] and two case reports [38,39]); and SYNJ1 (one original article [40] and one case report [41]).

\subsection{Genetic Results}

The majority of analyzed conditions are autosomal dominant (AD), 5 five (AP3B2, PCDH12, SLC13A5, SYNJ1 and WWOX) are autosomal recessive, and two are X-linked (CDKL5 and SMC1A).

Segregation analysis was performed in all cases except: $2 / 33$ patients within the CACNA1E cohort (parents unavailable) [42], and 2/17 cases with SCN2A variants (father unavailable, mother tested negative) [36].

Among AD conditions, detected variants were de novo in all cases except the 2 related patients with the FHF1 variant (suspected germline mosaicism) [43],1/7 cases with GNAO1 variants (suspected germline mosaicism) [15], 2/17 unrelated cases with paternally inherited SCN2A variants [36,37], and $1 \mathrm{KCNQ} 2$ variant, inherited from the affected mother [22].

In tested AR conditions, parents were heterozygous carriers [29,30,44-46].

For X-linked conditions [47,48], variants were confirmed to be de novo (Table S1).

Classification according to gene function is reported in Table 1. 
Table 1. Function of genes involved in neonatal-onset epilepsies/EE and MD.

\begin{tabular}{cc}
\hline Functional Role & Gene Name \\
\hline Channelopathies & CACNA1E, KCNQ2, SCN2A, SCN8A \\
\hline ATPase & ATP1A3 \\
\hline Synaptopathies & GNAO1 \\
\hline G protein transduction & FOXG1 \\
\hline Transcription factors & CDKL5, SMC1A, PURA \\
\hline Transcription regulators & PCDH12 \\
\hline Neuronal connectivity/signal \\
transduction & RHOBTB2 \\
\hline Ubiquitination & GRIN2B \\
\hline Receptors & WWOX \\
\hline Enzymes & FHF1 \\
\hline Growth factors & SLC13A5 \\
\hline Transporters
\end{tabular}

\subsection{Clinical Findings}

\subsubsection{Epilepsy}

The main seizure types at onset include "focal" (30 patients, 14 with clonic seizures), tonic (24), epileptic spasms (ES) (14), and myoclonic (10) [6,15,17-19,22,25-28,31-35,39,42-56]. Thirteen patients had tonic-clonic seizures [6,15,16,26,33,54,56,57], twelve had subtle seizures [19,29,30,36,38,39,41,44,46,54,58], two had "multifocal" seizures [36,52] and one had "generalized" [57]. No information on neonatal seizure semiology is available in three $[13,14,59]$ (Table S1). A high rate of status epilepticus is reported with SLC13A5 pathogenic variants [29,30]. KCNQ2-related encephalopathy is associated with focal tonic, followed by clonic jerks and frequent dysautonomic features. Similar semiology of tonic and/or clonic phenomena, possibly with deaturation or apnea, can also be detected in SCN2A-positive patients.

The most frequent electroclinical diagnosis is early onset EE (EOEE), reported for $22 / 27(81.5 \%)$ genes. Electroclinical classification according to genetic diagnosis is detailed in Table 2.

Table 2. Electroclinical syndromes according to genetic etiology.

\begin{tabular}{cc}
\hline Electroclinical Phenotype & Gene Name \\
\hline EOEE $(22 / 27 ; 81.5 \%)$ & AP3B2, ATP1A3, CACNA1E, CDKL5, DNM1, FOXG1, FXF1, \\
& GABRA1, GABRB2, GABRB3, GABRG2, GNAO1, KCNQ2, \\
PCDH12, RHOBTB2, SCN2A, SCN8A, SLC13A5, SMC1A, \\
STXBP1, SYNJ1, WWOX
\end{tabular}

\subsubsection{Neurological Examination}

Hypotonia (especially axial) can be present in $22(81.5 \%)$ conditions: AP3B2, ATP1A3, CACNA1E, CDKL5, DNM1, FHF1, GABRB2, GABRB3, GABRG2, GRIA2, GNAO1, KCNQ2, PCDH12, PURA, RHOBTB2, SCN2A, SCN8A, SLC13A5, STXBP1, SYNJ1, VAMP2, and WWOX; microcephaly in 12 (44\%): AP3B2, DNM1, FHF1, GABRA1, GABRB2, GRIA2, GNAO1, PCDH12, SCN8A, and SLC13A5 (absent in neonatal-onset cases), postnatal in 
$A T P 1 A 3$, head growth deceleration in CDKL5. On the contrary, macrocephaly is rare (CACNA1E) [42].

\subsubsection{Neurodevelopmental Aspects}

$\mathrm{DD}$ and/or intellectual disability (ID) can develop in all disorders, while autistic features are described in 6/27 (22\%: CDKL5, KCNQ2, GRIN2B, SCN2A, STXBP1, and VAMP2), regression in 7/27 (26\%: AP3B2, CACNA1E, CDKL5, FHF1, GRIN2B, SCN8A, and STXBP1), and stagnation in 2 (7\%: GABRB3, GNAO1).

\subsubsection{Movement Disorder}

MD is hyperkinetic in $23 / 27$ ( $85 \%$ ), while a hypokinetic disorder can develop in WWOX-, STXBP1-, and GRIA2-related disorders (Table 3; Table S1).

Table 3. Movement disorder semiology according to genetic etiology.

\begin{tabular}{|c|c|}
\hline Type of MD & Gene Name \\
\hline \multicolumn{2}{|c|}{ HYPERKINETIC MD } \\
\hline Ataxia & FHF1 KCNQ2 SCN8A STXBP1 SLC13A5 \\
\hline Dystonia & $\begin{array}{c}\text { AP3B2 CACNA1E DNM1 GABRB2 GNAO1 KCNQ2 } \\
\text { PCDH12 RHOBTB2 SCN2A SCN8A STXBP1 WWOX } \\
\text { SLC13A5 SYNJ1 }\end{array}$ \\
\hline Status dystonicus & GNAO1 \\
\hline Stereotypies & $\begin{array}{c}\text { AP3B2 CDKL5 FOXG1 KCNQ2 GABRG2 SCN2A } \\
\text { SMC1A STXBP1 }\end{array}$ \\
\hline Tremor & KCNQ2 SCN8A STXBP1 \\
\hline Chorea & $\begin{array}{c}\text { CACNA1E GNAO1 KCNQ2 (with fever) RHOBTB2 } \\
\text { SCN2A STXBP1 VAMP2 SLC13A5 }\end{array}$ \\
\hline Choreo-athethosis & GABRA1 STXBP1 SLC13A5 \\
\hline Athethosis & ATP1A3 PCDH12 \\
\hline Dyskinesia & $\begin{array}{c}\text { AP3B2 CACNA1E FOXG1 GABRB3 GNAO1 SCN8A } \\
\text { STXBP1 SLC13A5 KCNQ2 (myoclonus-like) }\end{array}$ \\
\hline Akathisia & GNAO1 \\
\hline Myoclonus & $\begin{array}{c}\text { CACNA1E GABRA1 GRIA2 KCNQ2 SCN8A STXBP1 } \\
\text { WWOX }\end{array}$ \\
\hline Oculogyric crises & GRIA2 SCN2A \\
\hline Paroxysmal dyskinesia & KCNMA1 RHOBTB2 \\
\hline Episodic ataxia & $S C N 2 A$ \\
\hline $\begin{array}{l}\text { Paroxysmal non-epileptic } \\
\text { polymorphous events }\end{array}$ & ATP1A3 SCN8A \\
\hline Paroxysmal involuntary movements & WWOX \\
\hline Startle/hyperekplexia & GNAO1 SCN8A STXBP1 WWOX \\
\hline \multicolumn{2}{|c|}{ HYPOKINETIC MD } \\
\hline \multicolumn{2}{|l|}{ Bradykinesia } \\
\hline Hypokinesia & GRIA2 WWOX \\
\hline Hypokinetic-rigid syndrome & STXBP1 \\
\hline \multicolumn{2}{|c|}{ UNSPECIFIED } \\
\hline & PURA \\
\hline
\end{tabular}


Age of MD onset was reported for 10/27 (37\%) monogenic conditions. Neonatal onset is described in 6 (myoclonus in GRIA2, KCNQ2, SCN8A and STXBP1, tremor in SCN8A, dystonia in $P C D H 12$, non-epileptic tonic and dystonic events, and episodic oculomotor abnormalities with tachycardia in $A T P 1 A 3)$. Infantile onset is described for paroxysmal non-epileptic events and athetosis in $A T P 1 A 3$, excessive startle, focal dystonia and reduced spontaneous movements in GNAO1, and dystonia and opistotonic posturing in SYNJ1. Between 1 and 3 years, hypokinesia and oculogyric crises develop in GRIA2, and stereotypies in SMC1A and STXBP1, while episodic ataxia develops in SCN2A-positive patients with previous benign familial infantile seizures (BFIS). In patients harboring STXBP1 pathogenic variants, ataxia and head nodding are reported from early childhood, while dystonia and tremor in late childhood. Parkinsonism can take place from adolescence. Non-further specified "early onset" dystonia, chorea, dyskinesia, myoclonus and non-specified hyperkinetic $\mathrm{MD}$ are reported with $C A C N A 1 E$, whereas, in the remaining conditions, age of MD onset was not reported.

\subsection{Neuroimaging Findings}

Brain MRI is unremarkable in most disorders (Table 4). Nonspecific findings include cerebral atrophy in $10(10 / 27,37 \%)$, white matter abnormalities (including hypomyelination) in $7(7 / 27,26 \%)$, and myelination delay in $7(7 / 27,26 \%)$. The range of additional findings is wide but shared by fewer conditions. PCDH12-related disorder has specific findings of midbrain, hypothalamus and optic trait dysplasia (Table 4).

Table 4. Brain MRI findings according to genetic etiology.

\begin{tabular}{|c|c|}
\hline Brain MRI Findings & Genes \\
\hline NORMAL & $\begin{array}{c}\text { CACNA1E, CDKL5, DNM1, FXF1, GABRA1, } \\
\text { GABRG2, GNAO1, GRIN2B, KCNMA1, KCNQ2, } \\
\text { PURA, SCN8A, SLC13A5, STXBP1, VAMP2, WWOX }\end{array}$ \\
\hline Cerebral atrophy & $\begin{array}{c}\text { ATP1A3, CACNA1E, FOXG, GABRA1, GNAO1, } \\
\text { KCNQ2, SCN8A, STXBP1 SYNJ1 }\end{array}$ \\
\hline $\begin{array}{l}\text { White matter abnormalities (including } \\
\text { hypomyelination) }\end{array}$ & $\begin{array}{c}\text { CACNA1E, GABRB2, GABRB3, GRIA2, KCNQ2, } \\
\text { SCN2A, SLC13A5 SYNJ1 (periventricular WM } \\
\text { gliosis) }\end{array}$ \\
\hline Cerebellar atrophy & FHF1, GABRA1, GRIA2 \\
\hline Corpus callosum hypoplasia & FOXG1,GABRA1, WWOX \\
\hline Thin CC & $\begin{array}{c}\text { AP3B2, CACNA1E, GNAO1, KCNQ2, SMC1A, SYNJ1, } \\
\text { WWOX }\end{array}$ \\
\hline Myelination delay & $\begin{array}{c}\text { ATP1A3, CACN1E, FOXG1, GNAO1, RHOBTB2, } \\
\text { SCN8A }\end{array}$ \\
\hline Basal Ganglia hyperintensities & $\begin{array}{c}A T P 1 A 3(\mathrm{GP}), C A C N A 1 E, \text { GNAO1 (GP), KCNQ2 (BG } \\
\text { and THALAMI, neonatal age), SCN2A }\end{array}$ \\
\hline Cortical malformations & FOXG1, KCNQ2 (simplified gyral pattern) \\
\hline Cerebellar hypoplasia & GRIA2 (vermis) \\
\hline Enlarged extra-axial space & $A P 3 B 2, W W O X$ \\
\hline Brainstem hyperintensities & $S C N 2 A$ \\
\hline $\begin{array}{l}\text { Midbrain, hypothalamus and optic trait } \\
\text { dysplasia }\end{array}$ & PCDH12 \\
\hline Small frontal lobes & $S M C 1 A$ \\
\hline Small thalami & KCNQ2 \\
\hline
\end{tabular}




\subsection{Presentation and Outcome According to Genetic Diagnosis \\ 3.4.1. Enzymes}

WWOX (WW domain-containing oxidoreductase): 5/20 cases had neonatal-onset epilepsy with associated MD. One additional patient also had suspected paroxysmal nonepileptic events. Seizure types at onset are described as focal clonic, focal non-specified, occipital, subtle (one each), and ES in two. Onset ranged between days 1 and 20. During follow-up, seizure types included spasm, tonic, tonic-clonic and absences. EEG can present interictal focal, or multifocal, discharges with posterior predominance. Associated findings include hypotonia with pyramidal signs and/or appendicular hypertonia, early onset scoliosis and/or kyphosis and frequently poor/absent eye contact, in some cases with abnormal evoked potentials or electroretinogram, and possible retinal degeneration. MD is strikingly hypokinetic with very limited spontaneous movements, while upper limbs' dystonia, myoclonus, startles, paroxysmal involuntary movements, and episodes of boxing/pedaling were also described [46].

\subsubsection{Synaptopathies}

AP3B2 (adaptor-related protein complex 3, beta-2 subunit): EOEE characterized by severe/profound DD, with possible psychomotor deterioration, poor visual contact with optic atrophy, and postnatal microcephaly. Patients usually present in infancy, but 2/12 $(16.7 \%)$ cases had neonatal onset with hypertonia and seizures (subtle in one and tonic in the second). EEG data are unavailable. Neurodevelopmental outcome is characterized by severe-to-profound DD and midline stereotypies. Additional phenotypes include dyskinesias and choreoathetosis. Age at onset and subsequent evolution are not reported. Epilepsy is usually drug-resistant, but in one of the two neonatal-onset cases, seizure freedom is reported [44].

DNM1 (dynamin 1): The common phenotype includes severe-to-profound ID, hypotonia and frequent $(76 \%)$ EE characterized by infantile spasms, frequently evolving into Lennox-Gastaut syndrome and drug resistance. The mean age at epilepsy onset is 7.6 months. However, 1/21 patients had neonatal-onset myoclonic epilepsy at 3 weeks of age, later followed by absence seizures in the context of profound DD, hypotonia followed by spasticity, microcephaly and dystonia. EEG shows background slowing. Long-term epilepsy outcome is reportedly good [49].

STXBP1 (syntaxin-binding protein 1): In two case series, 2/5 [33] and 4/5 [31] had neonatal-onset DEE with MD. Reported seizure semiology at onset includes mainly tonic, myoclonic and ES, although clonic and tonic-clonic seizures were also described. Seizure types at follow-up, when reported, include persistence of ES and tonic seizures, although focal impaired awareness, gelastic, and tonic-clonic are also enumerated. EEG is abnormal (either burst-suppression or multifocal). One case series reports seizure freedom from 6 months of age in 2 patients, and at 12 and 18 months in one each. Hypotonia, severe DD, and autistic features are frequent. The associated MD can be complex. Myoclonus has been described since the neonatal period, while stereotypies after 2 years, ataxia in childhood, and, interestingly, parkinsonian features were reported in two individuals (in one from 12 years, and in the second-followed up until 45 years of age-with unspecified onset). Head nodding, dystonia, chorea or choreathethosis, and dyskinesias are additional features with an unspecified age-of-onset [31,34].

VAMP2 (vesicle-associated membrane protein 2): 2/5 patients had hyperkinetic MD and epilepsy, with neonatal-onset in one. Seizure semiology is reported as initially focal, with ictal EEG characterized by fast rhythmic activity, evolving into sharp-and-slow-wave complexes, and, later, tonic-clonic seizures. The neurological phenotype is significant for hypotonia, cerebral visual impairment, severe ID with autistic and Rett-like features, and self-injurious behaviour. The patient also developed generalized chorea of unspecified onset [56].

SYNJ1 (Synaptojanin 1): Two articles report on three patients affected by neonatalonset refractory DEE, an early onset neurodegenerative course and premature death (be- 
tween 2 years, 4months and 8 years), caused by biallelic variants in the SYNJ1 gene. Seizure onset occurred between D1 and D12 of life, with eye blinking, hypertonus, bicycling, or eye deviation. EEG was abnormal/severely abnormal with multifocal discharges in all. Neurological examination progressed from hypotonia to severe spastic quadriparesis and dystonia with/without opistotonic posturing, developing since infancy (with partial response to clonazepam in one). DD is profound and accompanied by cortical visual impairment (2/3). In one case, thin corpus callosum, atrophy and gliosis were detected on a brain MRI, but the remaining two patients had normal findings when imaged $[40,41]$.

\subsubsection{ATPASEs}

ATP1A3 (sodium-potassium ATPase, alpha3 polypeptide): EOEE with seizure onset at $4 \mathrm{~h}$ and on the second day of life in two term newborns is described. No further description is provided. Subsequent refractory epilepsy was reported, but ictal semiology is not described. Both patients developed postnatal microcephaly and severe DD. Nonepileptic episodes featuring nystagmus, dysconjugate gaze, and decreased responsiveness started at 2 months of age, and athetotic movements from 11 months in one patient. The second experienced non-epileptic tonic and dystonic events, and episodic oculomotor abnormalities with tachycardia since the neonatal age [13,14].

\subsubsection{Channelopathies}

CACNA1E (calcium channel, voltage dependent, alpha-1E subunit): DE/EE with contractures, macrocephaly, and dyskinesias is reported. A total $4 / 30(13 \%)$ cases experienced neonatal onset of seizures: two with myoclonic seizures and two with ES. None developed an $\mathrm{MD}$, in contrast with the rest of the cohort, in which dystonia, dyskinesias, chorea and myoclonus were reported [42].

KCNQ2 (potassium channel, voltage gated, KQT-like subfamily, member 2): Typical seizure semiology consists of tonic versive seizure with clonic component and possible associated autonomic features (i.e., apnea). Neonatal EEG is severely abnormal, with multifocal random suppression with multifocal discharges. An association with hyperkinetic MD has been increasingly documented: dystonia or spastic-dystonic tetraparesis [20,21,23], paroxysmal "myoclonus-like" dyskinesia (reported in mother and son), ataxic/broad-based gait (two patients), hyperkinetic dyskinesia, mild distal tremor (at 2 years of age), and hand stereotypies (three reports). There is a single report on the occurrence of fever-sensitive chorea and myoclonus [24].

KCNMA1 (potassium channel, calcium-activated, large conductance, subfamily $\mathrm{M}$, alpha member 1): KCNMA1 pathogenic variants were first reported in a family with $\mathrm{AD}$ generalized epilepsy and paroxysmal non-kinesigenic dyskinesia. Typical age of onset is in infancy. In one paper, non-specified neonatal-onset seizures were reported in the context of severe DD, in association with later development of paroxysmal non-kinesigenic dyskinesia [59].

SCN2A (sodium channel, voltage-gated, type II, alpha subunit): 17 patients from 5 papers experience neonatal-onset epilepsy and subsequent MD. Of note, 6 harbor the same c.788C > T missense variant, which is a known hot spot, while 7 patients have a neonatal-onset DE/EE [34], and 10 have a benign-familial-infantile (BFIS) type 3 (BFIS3) phenotype. Seizures in the neonatal period are reported as focal, with multiple seizure types in all patients with DEE, including tonic and spasms; also, patients with a milder phenotype tend to present with tonic seizures, with/without a (hemi)clonic component and autonomic changes (apnea and desaturations). In one case, hypomotor semiology is described at seizure onset. In patients with DEE, EEG is normal or slow in five, and burstsuppression in two, but all with multifocal discharges, while mildly abnormal/normal background with focal sharp has been reported in BFIS3-cases. No cases experienced regression. Neurological examination is characterized by axial hypotonia in nine and appendicular hypertonia in four. DD is severe/profound in five, mild/moderate in three and normal in three. Autistic features are reported in just one case, in keeping with early 
onset epilepsy cases resulting from gain-of-function variants. MD is either in the form of stereotypies, opisthotonus or chorea (1 patient), oculogyric crises (2 patients), and dystonia (4 patients) [35], or in the form of episodic ataxia (10 cases, following BFIS3). Seizure control is reported in seven patients (between 3 and 13 months of age, when available), while episodic ataxia is ongoing, with variable response to acetazolamide. Brain MRI findings have been reported in one paper, showing white matter changes in seven cases, basal ganglia involvement in six, and brainstem involvement in two [36], while neuroimaging data in BFIS3 followed by episodic ataxia were not available [36-39].

SCN8A (sodium channel, voltage-gated, type VIII, alpha subunit): Neonatal-onset epilepsy with associated MD was reported in 1/22 [6], 1/19 [25] and 2/17 [26] cases, respectively. Seizure types are described as tonic with/without apnea, spasms, but also focal clonic. Multiple seizures develop during follow-up (tonic-clonic, focal with impaired awareness, episodes of status epilepticus). EEG, when reported, is slow, low voltage, or "burst-suppression-like" during sleep. Deterioration has been highlighted, and a posterior (temporo-parieto-occipital) prevalence of interictal discharges is consistently found [6]. Hypotonia, acquired microcephaly, and severe/profound DD are constant. Poor eye contact and cortical blindness seem very common (17/22 cases from the whole cohort in [6]). Coarse tremor, non-epileptic myoclonus, and exaggerated startle have been reported at birth, while dyskinesia, paroxysmal dystonic posturing, ataxia and dystonia have also been described, with unspecified age of onset [6].

\subsubsection{Transcription Regulators}

CDKL5 (cyclin-dependent kinase-like 5): Out of seven diagnosed cases, two had neonatal-onset epilepsy, with myoclonic and focal seizures. Neonatal EEG is not reported, but subsequent recordings show slow background with intermittent multifocal discharges. Both developed hand stereotypies with lack of purposeful hand movements, with dysautonomic features in one. Poor eye contact is present in both, and overt autistic features in one. In the whole cohort, choreiform movements are also described [47].

PURA (purine-rich element-binding protein A): A single patient out of 30 has been reported with neonatal-onset myoclonic seizures and moderate ID. Hand stereotypies and exaggerated startle response are described as consistent, but their presence is unknown in the only patient with neonatal-onset epilepsy. Other patients with PURA syndrome develop dystonia or ataxia/broad-based gait [55].

SMC1A (structural maintenance of chromosomes 1A): One patient with focal epilepsy, beginning within the first month, of life has been described. Semiology in the neonatal period was characterized by eyelid myoclonia, evolving into drug-resistant multifocal epilepsy. The patient was born with IUGR and congenital microcephaly. She developed hand stereotypies at 2 years of age. Outcome is significant for severe ID, spastic tetraparesis, poor eye contact. Additional clinical features include reflux, scoliosis, and dysmorphisms. $S M C 1 A$ pathogenic variants have been associated with Cornelia de Lange syndrome, but, at both extremes of the spectrum, severe cases with early onset epilepsy/EE or mildly affected patients are described [48].

\subsubsection{Transcription Factors}

FOXG1 (forkhead box G1): FOXG1 pathogenic variants are associated with a complex neurodevelopmental phenotype (postnatal microcephaly, DD and hyperkinetic MD with prominent stereotypes, and epilepsy), with a mean onset in early childhood. Some genotype-phenotype correlations have emerged, as frameshift and nonsense $\mathrm{N}$-terminus mutations are associated with greater severity and MRI anomalies. One case of neonatalonset epilepsy is reported in a series of 45 patients. The patient, now aged 8 years, is still experiencing less than one focal seizure/month [50]. 


\subsubsection{Growth Factors}

FGF12 (FHF1) (fibroblast growth factor 12): Two siblings affected by neonatal-onset EE with tonic seizures and a characteristic neonatal EEG pattern (interictal: severe background slowing and multifocal discharges, ictal: low voltage fast activity, followed by prolonged background suppression) with normal neurologic status prior to seizure onset, subsequently developed a complex phenotype with hypotonia, microcephaly, feeding difficulties, cerebral visual impairment with pale optic nerve disc, and limb ataxia. Both developed cerebellar atrophy in their childhood. Follow-up EEG reported in the first sibling at 5 months was hypsarrhythmic, with no detected infantile spasms. Disease course was degenerative and both died before age 7 [43].

\subsubsection{Receptors}

GABRA1 (gamma-aminobutyric acid receptor, alpha1): Although mean age at epilepsy onset is 2.6 months, in a series of 6 EOEE patients [51], two had neonatal onset EE (tonic in one and myoclonic - evolving to infantile spasms at 1.5 months-in the second). Clinical evolution of both patients is characterized by severe DD with intractable epilepsy in one, and progressive brain atrophy. The complex neurologic phenotype also features non-epileptic myoclonus in one and choreoathethosis (resolving at 2 years of age) in the second [51].

GABRB2 (gamma-aminobutyric acid receptor, beta-2): One neonatal-onset case is found out of seven $(1 / 7,14 \%)$. Epileptic seizures were described as tonic, focal and multifocal. EEG background is abnormal with multifocal discharges. Subsequent development is characterized by severe DD with hypotonia (followed by spasticity) and dystonia, and acquired microcephaly. Choreoathethosis and ataxia are described in infantile-onset cases [52].

GABRB3 (gamma-aminobutyric acid receptor, Beta-3): Among 22 cases of epilepsy/EE (with mean onset at 8.7 months), one patient experienced neonatal-onset EE. His seizure types are polymorphous (focal, tonic-clonic, spasms). He has severe DD and experienced stagnation aged 3 months [53].

GABRG2 (gamma-aminobutyric acid receptor, gamma-2): In a cohort of 5 patients harbouring a recurrent c.316G > A; p.A106T pathogenic variant, two had intractable, neonatal-onset epilepsy (not further characterized: one; ictal apnea: one), followed by focal versive, myoclonic and tonic-clonic seizures associated with hypotonia, severe $\mathrm{DD}$, cortical visual impairment, and stereotypies in one [60].

GRIA2 (glutamate receptor, ionotropic AMPA 2): 2/24 patients ( $8 \%$ ) with neurodevelopmental disorder and $\mathrm{EE}$ had neonatal-onset seizures and $\mathrm{MD}$. Seizures at onset were tonic hypomotor, with subtle phenomena and myoclonic jerks or eyelid myoclonia. Subsequent seizure types included focal and ES. Neonatal EEG showed a normal background with multifocal discharges, later evolving into high-voltage-slow. Neurological examination revealed hypotonia, DD and decelerating head growth, or acquired microcephaly. The associated neonatal MD is characterized by non-epileptic myoclonus and exaggerated startle, while, at 3 years of age, one patient is described as hypokinetic with oculogyric crises [54].

GRIN2B (glutamate receptor, ionotropic, N-Methyl-D Aspartate, subunit 2B): The only patient with neonatal-onset epilepsy had subtle seizures, followed by spasms. He has severe DD and a dyskinetic MD. Brain MRI is normal. No detailed information is available on neonatal EEG or subsequent epilepsy course. The mean age at epilepsy onset in the cohort is 6.5 years, and the core phenotype is represented by a neurodevelopmental disorder featuring hypotonia, MD (choreo-athethosis, dystonia), cortical visual impairment and cerebral volume loss [58].

\subsubsection{G-PROTEIN Transduction}

GNAO1 (guanine nucleotide-binding protein, alpha-activating activity polypeptide O): GNAO1 encephalopathy clinically encompasses a complex neurologic phenotype associat- 
ing severe and disabling hyperkinetic MD with/without EE. Neonatal-onset EE occurred in 7/26 of reviewed cases, typically with tonic, tonic and clonic seizures, or spasms, although focal seizures with apnea (later evolving into focal hypomotor with dysautonomic features) were also reported. EEG is severely abnormal with multifocal discharges or burstsuppression. Six patients developed an MD (dystonic in three, dyskinetic or choreic in two each, akathisia in one) and, during the follow-up, severe-to-profound DD, swallowing difficulties, and sometimes microcephaly [15-19].

\subsubsection{Neuronal Connectivity/Signal Transduction}

PCDH12 (protocadherin 12): 3/4 in a consanguineous family had neonatal-onset focal, tonic seizures or spasms. EEG showed variable findings (focal, multifocal or hypsarrhythmia). They had visual impairment, hypotonia and microcephaly, and profound DD. Congenital dystonia was reported in $3 / 4$ cases [45].

\subsubsection{Ubiquitination}

RHOBTB2 (rho-related BTB domain-containing protein 2): infantile-onset DE/EE and $\mathrm{MD}$ (chronic and/or paroxysmal) in the context of severe DD are the main clinical features. One out of ten patients has been reported with "generalized" neonatal-onset epilepsy. MD is complex, incorporating chorea and dystonia, together with paroxysmal dyskinetic attacks. Epilepsy outcome is usually good, as it was in this neonatal-onset case, while MD is ongoing [57].

\subsubsection{Transporters}

SLC13A5 (solute carrier, family 13, member 5): Patients present a consistent phenotype: neonatal-onset EOEE with clonic and/or subtle seizures and a high rate of status epilepticus. Ictal EEG is characterized by multifocal discharges with predominant temporal or temporooccipital foci. A high proportion of cases (5/7 in [28]) have complex MD, with ataxia, choreo-athethosis, dystonia, and/or dyskinesia. Age of onset is not reported. Variable DD is always present. Microcephaly can be a feature. The most consistent additional report is hypodontia or teeth hypoplasia. White-matter changes can be reminiscent of periventricular leukomalacia [30].

\section{Discussion}

Although more than 100 genes have been associated with complex monogenic neurologic disorders featuring pediatric-onset DE/EE and MD [61-63], this association has been less investigated in newborns. As a result, the number of reviewed studies is low and, for $70 \%$ of genes, only single papers were available.

This likely reflects our search strategy's exclusion of neurometabolic disorders. In fact, the association between epilepsy/EE and MD in newborns should raise suspicion of neurometabolic disorders, especially mitochondrial [7] or neurotransmitters disorders (although highly heterogeneous) $[64,65]$. While biomarkers can help diagnostic work-up in these conditions $[66,67]$, this is not the case with genetic diagnoses, where accurate semiological, EEG and neuroimaging data evaluations become imperative.

This review highlights that, although singularly rare, the number of disorders with possible neonatal onset is high, with 27 different genes involved, all playing key roles in cellular functions critical for brain development from its earliest stages [68]. The most conspicuous groups are neurotransmitters receptors, ion channels and synaptic formation and function. From a clinical standpoint, this translates into disrupting crucial neurodevelopmental trajectories, resulting in complex neurodevelopmental disorders featuring epilepsy/EE-DE, MD, but also DD or ID developing in all reviewed conditions. Furthermore, a high rate of microcephaly and/or decelerating head growth is present, with frequent co-occurrence of autistic features, adding evidence that neurodevelopmental disorders have a strong genetic component and comprise a range of co-existing morbidities [68,69]. Furthermore, as can be usefully exemplified by CDKL5, the complex interplay 
with other gene products, i.e., $M E C P 2$ (methyl $C p G$ binding protein 2), which works as a transcriptional repressor/activator, results in partially overlapping, complex neurodevelopmental phenotypes falling within the so-called Rett syndrome spectrum [70]. None of the patients with monogenic disorders presented a fully "benign" phenotype; even though, in some, a partial or transient seizure control was achieved.

Although we searched for both "epilepsies" and "DE-EE", this population is enriched with EE and mainly falls into an EOEE diagnosis. Therefore, the prevalent seizure types in the neonatal period are tonic or myoclonic. With recent advances in genetic testing, there has been renewed interest in the relationship between seizure semiology and etiology in newborns, documenting higher occurrence of myoclonic and "sequential" seizures with burst-suppression in genetic aetiologies [71]. An important exception is represented by $S C N 2 A$ cases, in which BFIS are accompanied by no or mild DD, seizure freedom since infancy, and are followed by the development of childhood-onset episodic ataxia.

As far as MD is involved, the majority of patients develop chronic hyperkinetic disorders. Age of onset is often lacking, but it falls within the neonatal period only in a minority of cases, with myoclonus or myoclonus-like dyskinesia, dystonia (including opistotonus), athethosis, tremors, or startle. Only in patients with WWOX gene variants there is an associated early onset hypokinetic MD with little or no psychomotor development from birth [46]. In the remaining cases, hypokinetic MD develops later in the disease course: in early childhood in GRIA2-related disorder, during teenage years in STXBP1, with parkinsonism [33,34]. However, as hyperkinetic MD might be easier to recognize, a potential bias cannot be completely excluded.

Neuroimaging is often unremarkable during the neonatal period, but, afterwards, progressive cerebellar or cerebral degenerative changes can be detected [6,15-19,43,51-55].

As in the majority of cases, MD onset occurs during infancy or childhood, and neonatalonset MD can be useful to prioritize differential diagnosis: neonatal-onset hypokinetic MD appears exceptional and highly suggestive for WWOX-related disorders. Neurometabolic conditions being ruled out, hyperkinetic neonatal-onset MD should first raise suspicion of an SCN8A or STXBP1-related disorder, as these are associated with myoclonus/myoclonuslike dyskinesia (STXBP1, but also reported in KCNQ2), dystonia and/or opistotonus (SCN8A, although also described in PCDH12), tremors (both conditions), and startles (both, plus GRIA2). Complex paroxysmal episodes of dystonic-tonic posturing with eye movement abnormalities should raise suspicion of an ATP1A3-related disorder, while paroxysmal tonic episodes alternating with hypotonia have been documented in $S C N 8 A$. Outside these conditions, data to set up the diagnostic process since the first days of life mainly pertain to the epilepsy phenotype, in some cases assisted by neuroimaging data. However, as already discussed, the majority of patients will present with EOEE, often characterized by burst-suppression or a multifocal pattern and tonic/myoclonic seizures with limited specificity, as only KCNQ2 encephalopathy has been robustly associated with a typical seizure type. In clinical practice, this lack of specificity results in a high priority of NGS panels or whole exome sequencing in the diagnostic work-up.

We documented a high rate of missense variants [72,73], reflecting the notion that these can be frequently deleterious in humans and contribute to complex disorders [74]. For AD conditions, it is clinically relevant to highlight that, despite the vast majority of variants causing severe EE/DE phenotypes occurring de novo, parental mosaicism should always be considered and risk assessment with high depth coverage offered to parents.

Detailed information about neonatal ictal semiology and EEG findings is missing more often than in older age groups, highlighting the need for better characterization of ictal semiology and neonatal ictal, as well as interictal EEG characteristics in this age group.

Although precision medicine is a clinical practice in only a few conditions (KCNQ2, $S C N 2 A, S C N 8 A$ ), it is mandatory to improve our knowledge of early presenting features. To this end, lines of future research should also focus on defining age ranges of onset, clinical features, evolution, and therapeutic strategies for the associated MD, as these are often less discussed compared to epileptic phenotypes. 
Supplementary Materials: The following are available online at https: / www.mdpi.com/article/ 10.3390/ijms22084202/s1. Table S1: Data collection sheets with detailed information from the 49 included articles.

Author Contributions: C.S. performed the literature review, wrote the first draft of the manuscript and approved it in its final form; C.F. critically reviewed the manuscript and approved it in its final form; A.P. contributed to the classification of genetic data, critically reviewed the manuscript and approved it in its final form; V.L. conceived the study, critically reviewed the manuscript for intellectual content and approved it in its final form; F.P. supervised the writing of the manuscript, critically reviewed it for intellectual content and approved it in its final form. All authors have read and agreed to the published version of the manuscript.

Funding: The APC was funded by Research Budget, year 2021, of the AUSL-IRCCS di Reggio Emilia.

Conflicts of Interest: The authors declare no conflict of interest.

\section{References}

1. Pisani, F.; Spagnoli, C.; Fusco, C. EEG monitoring of the epileptic newborn. Curr. Neurol. Neurosci. Rep. 2020, 20, 6. [CrossRef]

2. Pisani, F.; Spagnoli, C.; Falsaperla, R.; Nagarajan, L.; Ramantani, G. Seizures in the neonate: A review of etiologies and outcomes. Seizure 2021, 85, 48-56. [CrossRef]

3. Shellhaas, R.A.; Wusthoff, C.J.; Tsuchida, T.N.; Glass, H.C.; Chu, C.J.; Massey, S.L.; Soul, J.S.; Wiwattanadittakun, N.; Abend, N.S.; Cilio, M.R.; et al. Profile of neonatal epilepsies: Characteristics of a prospective US cohort. Neurology 2017, 89, 893-899. [CrossRef]

4. Miceli, F.; Soldovieri, M.V.; Joshi, N.; Weckhuysen, S.; Cooper, E.; Taglialatela, M. KCNQ2-Related Disorders. In GeneReviews ${ }^{\circledR}$ [Internet]; Adam, M.P., Ardinger, H.H., Pagon, R.A., Wallace, S.E., Bean, L.J.H., Stephens, K., Amemiya, A., Eds.; Seattle (WA): Seattle, DC, USA, 1993-2020.

5. Wolff, M.; Johannesen, K.M.; Hedrich, U.B.S.; Masnada, S.; Rubboli, G.; Gardella, E.; Lesca, G.; Ville, D.; Milh, M.; Villard, L. Genetic and phenotypic heterogeneity suggest therapeutic implications in SCN2A-related disorders. Brain 2017, 140, 1316-1336. [CrossRef]

6. Gardella, E.; Marini, C.; Trivisano, M.; Fitzgerald, M.P.; Alber, M.; Howell, K.B.; Darra, F.; Siliquini, S.; Bölsterli, B.K.; Masnada, S.; et al. The phenotype of SCN8A developmental and epileptic encephalopathy. Neurology 2018, 91, e1112-e1124. [CrossRef] [PubMed]

7. Yu, J.Y.; Pearl, P.L. Metabolic causes of epileptic encephalopathy. Epilepsy Res. Treat. 2013, 2013, 124934.

8. Liberati, A.; Altman, D.G.; Tetzlaff, J.; Mulrow, C.; Gøtzsche, P.C.; Ioannidis, J.P.; Clarke, M.; Devereaux, P.J.; Kleijnen, J.; Moher, D. The PRISMA statement for reporting systematic reviews and meta-analyses of studies that evaluate health care interventions: Explanation and elaboration. J. Clin. Epidemiol. 2009, 62, 1-34. [CrossRef] [PubMed]

9. Scheffer, I.E.; Berkovic, S.; Capovilla, G.; Connolly, M.B.; French, J.; Guilhoto, L.; Hirsch, E.; Jain, S.; Mathern, G.W.; Moshé, S.L.; et al. ILAE classification of the epilepsies: Position paper of the ILAE Commission for Classification and Terminology. Epilepsia 2017, 58, 512-521. [CrossRef] [PubMed]

10. Fahn, S.; Jankovic, J.; Hallett, M. Principles and Practice of MovementDisorders, 2nd ed.; Elsevier: Philadelphia, PA, USA, 2011.

11. Richards, C.S.; Bale, S.; Bellissimo, D.B.; Das, S.; Grody, W.W.; Hegde, M.R.; Lyon, E.; Ward, B.E. Molecular Subcommittee of the ACMG Laboratory Quality Assurance Committee. ACMG recommendations for standards for interpretation and reporting of sequence variations: Revisions 2007. Genet. Med. 2008, 10, 294-300. [CrossRef]

12. Oxford Centre for Evidence-based Medicine. Available online: https://www.cebm.ox.ac.uk/resources/levels-of-evidence/ oxford-centre-for-evidence-based-medicine-levels-of-evidence-march-2009 (accessed on 16 April 2021).

13. Paciorkowski, A.R.; McDaniel, S.S.; Jansen, L.A.; Tully, H.; Tuttle, E.; Ghoneim, D.H.; Tupal, S.; Gunter, S.A.; Vasta, V.; Zhang, Q. Novel mutations in ATP1A3 associated with catastrophic early life epilepsy, episodic prolonged apnea, and postnatal microcephaly. Epilepsia 2015, 56, 422-430. [CrossRef] [PubMed]

14. Ishihara, N.; Inagaki, H.; Miyake, M.; Kawamura, Y.; Yoshikawa, T.; Kurahashi, H. A case of early onset life-threatening epilepsy associated with a novel ATP1A3 gene variant. Brain Dev. 2019, 41, 285-291. [CrossRef]

15. Kelly, M.; Park, M.; Mihalek, I.; Rochtus, A.; Gramm, M.; Pérez-Palma, E.; Axeen, E.T.; Hung, C.Y.; Olson, H.; Swanson, L.; et al. Spectrum of neurodevelopmental disease associated with the GNAO1 guanosine triphosphate-binding region. Epilepsia 2019, 60, 406-418. [CrossRef]

16. Saitsu, H.; Fukai, R.; Ben-Zeev, B.; Sakai, Y.; Mimaki, M.; Okamoto, N.; Suzuki, Y.; Monden, Y.; Saito, H.; Tziperman, B. Phenotypic spectrum of GNAO1 variants: Epileptic encephalopathy to involuntary movements with severe developmental delay. Eur. J. Hum. Genet. 2016, 24, 129-134. [CrossRef] [PubMed]

17. Nakamura, K.; Kodera, H.; Akita, T.; Shiina, M.; Kato, M.; Hoshino, H.; Terashima, H.; Osaka, H.; Nakamura, S.; Tohyama, J. De Novo mutations in GNAO1, encoding a G $\alpha$ o subunit of heterotrimeric G proteins, cause epileptic encephalopathy. Am. J. Hum. Genet. 2013, 93, 496-505. [CrossRef] [PubMed] 
18. Schorling, D.C.; Dietel, T.; Evers, C.; Hinderhofer, K.; Korinthenberg, R.; Ezzo, D.; Bönnemann, C.G.; Kirschner, J. Expanding Phenotype of De Novo Mutations in GNAO1: Four New Cases and Review of Literature. Neuropediatrics 2017, 48, 371-377. [PubMed]

19. Marcé-Grau, A.; Dalton, J.; López-Pisón, J.; García-Jiménez, M.C.; Monge-Galindo, L.; Cuenca-León, E.; Giraldo, J.; Macaya, A. GNAO1 encephalopathy: Further delineation of a severe neurodevelopmental syndrome affecting females. Orphanet. J. Rare Dis. 2016, 11, 38. [CrossRef] [PubMed]

20. Weckhuysen, S.; Mandelstam, S.; Suls, A.; Audenaert, D.; Deconinck, T.; Claes, L.R.; Deprez, L.; Smets, K.; Hristova, D.; Yordanova, I.; et al. KCNQ2 encephalopathy: Emerging phenotype of a neonatal epileptic encephalopathy. Ann. Neurol. 2012, 71, 15-25. [CrossRef] [PubMed]

21. Weckhuysen, S.; Ivanovic, V.; Hendrickx, R.; Van Coster, R.; Hjalgrim, H.; Møller, R.S.; Grønborg, S.; Schoonjans, A.S.; Ceulemans, B.; Heavin, S.B.; et al. Extending the KCNQ2 encephalopathy spectrum: Clinical and neuroimaging findings in 17 patients. Neurology 2013, 81, 1697-1703. [CrossRef]

22. Blumkin, L.; Suls, A.; Deconinck, T.; De Jonghe, P.; Linder, I.; Kivity, S.; Dabby, R.; Leshinsky-Silver, E.; Lev, D.; Lerman-Sagie, T. Neonatal seizures associated with a severe neonatal myoclonus like dyskinesia due to a familial KCNQ2 gene mutation. Eur. J. Paediatr. Neurol. 2012, 16, 356-360. [CrossRef]

23. Spagnoli, C.; Salerno, G.G.; Iodice, A.; Frattini, D.; Pisani, F.; Fusco, C. KCNQ2 encephalopathy: A case due to a de novo deletion. Brain Dev. 2018, 40, 65-68. [CrossRef]

24. Dhamija, R.; Goodkin, H.P.; Bailey, R.; Chambers, C.; Brenton, J.N. A case of KCNQ2-associated movement disorder triggered by fever. J. Child. Neurol. 2017, 32, 1123-1124. [CrossRef]

25. Denis, J.; Villeneuve, N.; Cacciagli, P.; Mignon-Ravix, C.; Lacoste, C.; Lefranc, J.; Napuri, S.; Damaj, L.; Villega, F.; Pedespan, J.M.; et al. Clinical study of 19 patients with SCN8A-related epilepsy: Two modes of onset regarding EEG and seizures. Epilepsia 2019, 60, 845-856. [CrossRef]

26. Schreiber, J.M.; Tochen, L.; Brown, M.; Evans, S.; Ball, L.J.; Bumbut, A.; Thewamit, R.; Whitehead, M.T.; Black, C.; Boutzoukas, E.; et al. A multi-disciplinary clinic for SCN8A-related epilepsy. Epilepsy Res. 2020, 159, 106261. [CrossRef]

27. Vaher, U.; Nõukas, M.; Nikopensius, T.; Kals, M.; Annilo, T.; Nelis, M.; Ounap, K.; Reimand, T.; Talvik, I.; Ilves, P.; et al. De novo SCN8A mutation identified by whole-exome sequencing in a boy with neonatal epileptic encephalopathy, multiple congenital anomalies, and movement disorders. J. Child. Neurol. 2014, 29, NP202-6. [CrossRef]

28. Singh, R.; Jayapal, S.; Goyal, S.; Jungbluth, H.; Lascelles, K. Early-onset movement disorder and epileptic encephalopathy due to de novo dominant SCN8A mutation. Seizure 2015, 26, 69-71. [CrossRef]

29. Thevenon, J.; Milh, M.; Feillet, F.; St-Onge, J.; Duffourd, Y.; Jugé, C.; Roubertie, A.; Héron, D.; Mignot, C.; Raffo, E.; et al. Mutations in SLC13A5 cause autosomal-recessive epileptic encephalopathy with seizure onset in the first days of life. Am. J. Hum. Genet. 2014, 95, 113-120. [CrossRef]

30. Hardies, K.; de Kovel, C.G.; Weckhuysen, S.; Asselbergh, B.; Geuens, T.; Deconinck, T.; Azmi, A.; May, P.; Brilstra, E.; Becker, F.; et al. Recessive mutations in SLC13A5 result in a loss of citrate transport and cause neonatal epilepsy, developmental delay and teeth hypoplasia. Brain 2015, 138 Pt 11, 3238-3250. [CrossRef]

31. Milh, M.; Villeneuve, N.; Chouchane, M.; Kaminska, A.; Laroche, C.; Barthez, M.A.; Gitiaux, C.; Bartoli, C.; Borges-Correia, A.; Cacciagli, P.; et al. Epileptic and nonepileptic features in patients with early onset epileptic encephalopathy and STXBP1 mutations. Epilepsia 2011, 52, 1828-1834. [CrossRef] [PubMed]

32. Allen, N.M.; Conroy, J.; Shahwan, A.; Lynch, B.; Correa, R.G.; Pena, S.D.; McCreary, D.; Magalhães, T.R.; Ennis, S.; Lynch, S.A.; et al. Unexplained early onset epileptic encephalopathy: Exome screening and phenotype expansion. Epilepsia 2016, 57, e12-e17. [CrossRef] [PubMed]

33. Rezazadeh, A.; Uddin, M.; Snead, O.C., 3rd; Lira., V.; Silberberg., A.; Weiss, S.; Donner, E.J.; Zak, M.; Bradbury, L.; Scherer, S.W.; et al. STXBP1 encephalopathy is associated with awake bruxism. Epilepsy Behav. 2019, 92, 121-124. [CrossRef] [PubMed]

34. Keogh, M.J.; Daud, D.; Pyle, A.; Duff, J.; Griffin, H.; He, L.; Alston, C.L.; Steele, H.; Taggart, S.; Basu, A.P.; et al. A novel de novo STXBP1 mutation is associated with mitochondrial complex I deficiency and late- onset juvenile-onset parkinsonism. Neurogenetics 2015, 16, 65-67. [CrossRef]

35. Howell, K.B.; McMahon, J.M.; Carvill, G.L.; Tambunan, D.; Mackay, M.T.; Rodriguez-Casero, V.; Webster, R.; Clark, D.; Freeman, J.L.; Calvert, S.; et al. SCN2A encephalopathy: A major cause of epilepsy of infancy with migrating focal seizures. Neurology 2015, 85, 958-966. [CrossRef]

36. Schwarz, N.; Hahn, A.; Bast, T.; Müller, S.; Löffler, H.; Maljevic, S.; Gaily, E.; Prehl, I.; Biskup, S.; Joensuu, T.; et al. Mutations in the sodium channel gene SCN2A cause neonatal epilepsy with late-onset episodic ataxia. J. Neurol. 2016, 263, 334-343. [CrossRef]

37. Schwarz, N.; Bast, T.; Gaily, E.; Golla, G.; Gorman, K.M.; Griffiths, L.R.; Hahn, A.; Hukin, J.; King, M.; Korff, C.; et al. Clinical and genetic spectrum of SCN2A-associated episodic ataxia. Eur. J. Paediatr. Neurol. 2019, 23, 438-447. [CrossRef] [PubMed]

38. Gorman, K.M.; King, M.D. SCN2A p.Ala263Val variant a phenotype of neonatal seizures followed by paroxysmal ataxia in toddlers. Pediatr. Neurol. 2017, 67, 111-112. [CrossRef] [PubMed]

39. Johannesen, K.M.; Miranda, M.J.; Lerche, H.; Møller, R.S. Letter to the editor: Confirming neonatal seizure and late onset ataxia in SCN2A Ala263Val. J. Neurol. 2016, 263, 1459-1460. [CrossRef] [PubMed] 
40. Hardies, K.; Cai, Y.; Jardel, C.; Jansen, A.C.; Cao, M.; May, P.; Djémié, T.; Hachon Le Camus, C.; Keymolen, K. Loss of SYNJ1 dual phosphatase activity leads to early onset refractory seizures and progressive neurological decline. Brain 2016, 139, $2420-2430$. [CrossRef]

41. Samanta, D.; Arya, K. Electroclinical findings of SYNJ1 epileptic encephalopathy. J. Pediatr. Neurosci. 2020, 15, $29-33$.

42. Helbig, K.L.; Lauerer, R.J.; Bahr, J.C.; Souza, I.A.; Myers, C.T.; Uysal, B.; Schwarz, N.; Gandini, M.A.; Huang, S.; Keren, B.; et al. De Novo Pathogenic Variants in CACNA1E Cause Developmental and Epileptic Encephalopathy with Contractures, Macrocephaly, and Dyskinesias. Am. J. Hum. Genet. 2018, 103, 666-678. [CrossRef]

43. Siekierska, A.; Isrie, M.; Liu, Y.; Scheldeman, C.; Vanthillo, N.; Lagae, L.; de Witte, P.A.; Van Esch, H.; Goldfarb, M.; Buyse, G.M. Gain-of-function FHF1 mutation causes early-onset epileptic encephalopathy with cerebellar atrophy. Neurology 2016, 86, 2162-2170. [CrossRef]

44. Assoum, M.; Philippe, C.; Isidor, B.; Perrin, L.; Makrythanasis, P.; Sondheimer, N.; Paris, C.; Douglas, J.; Lesca, G.; Antonarakis, S.; et al. Autosomal-Recessive Mutations in AP3B2, Adaptor-Related Protein Complex 3 Beta 2 Subunit, Cause an Early-Onset Epileptic Encephalopathy with Optic Atrophy. Am. J. Hum. Genet. 2016, 99, 1368-1376. [CrossRef]

45. Aran, A.; Rosenfeld, N.; Jaron, R.; Renbaum, P.; Zuckerman, S.; Fridman, H.; Zeligson, S.; Segel, R.; Kohn, Y.; Kamal, L.; et al. Loss of function of PCDH12 underlies recessive microcephaly mimicking intrauterine infection. Neurology 2016, 86, 2016-2024. [CrossRef]

46. Piard, J.; Hawkes, L.; Milh, M.; Villard, L.; Borgatti, R.; Romaniello, R.; Fradin, M.; Capri, Y.; Héron, D.; Nougues, M.C.; et al. The phenotypic spectrum of WWOX-related disorders: 20 additional cases of WOREE syndrome and review of the literature. Genet. Med. 2019, 21, 1308-1318. [CrossRef]

47. Russo, S.; Marchi, M.; Cogliati, F.; Bonati, M.T.; Pintaudi, M.; Veneselli, E.; Saletti, V.; Balestrini, M.; Ben-Zeev, B.; Larizza, L. Novel mutations in the CDKL5 gene, predicted effects and associated phenotypes. Neurogenetics 2009, 10, 241-250. [CrossRef] [PubMed]

48. Lebrun, N.; Lebon, S.; Jeannet, P.Y.; Jacquemont, S.; Billuart, P.; Bienvenu, T. Early-onset encephalopathy with epilepsy associated with a novel splice site mutation in SMC1A. Am. J. Med. Genet. Part. A 2015, 167, 3076-3081. [CrossRef]

49. von Spiczak, S.; Helbig, K.L.; Shinde, D.N.; Huether, R.; Pendziwiat, M.; Lourenço, C.; Nunes, M.E.; Sarco, D.P.; Kaplan, R.A.; Dlugos, D.J.; et al. DNM1 encephalopathy: A new disease of vesicle fission. Neurology 2017, 89, 385-394. [CrossRef] [PubMed]

50. Vegas, N.; Cavallin, M.; Maillard, C.; Boddaert, N.; Toulouse, J.; Schaefer, E.; Lerman-Sagie, T.; Lev, D.; Magalie, B.; Moutton, S.; et al. Delineating FOXG1 syndrome: From congenital microcephaly to hyperkinetic encephalopathy. Neurol. Genet. 2018, 4, e281. [CrossRef] [PubMed]

51. Kodera, H.; Ohba, C.; Kato, M.; Maeda, T.; Araki, K.; Tajima, D.; Matsuo, M.; Hino-Fukuyo, N.; Kohashi, K.; Ishiyama, A.; et al. De novo GABRA1 mutations in Ohtahara and West syndromes. Epilepsia 2016, 57, 566-573. [CrossRef] [PubMed]

52. Hamdan, F.F.; Myers, C.T.; Cossette, P.; Lemay, P.; Spiegelman, D.; Laporte, A.D.; Nassif, C.; Diallo, O.; Monlong, J.; Cadieux-Dion, M.; et al. High Rate of Recurrent De Novo Mutations in Developmental and Epileptic Encephalopathies. Am. J. Hum. Genet. 2017, 101, 664-685. [CrossRef]

53. Møller, R.S.; Wuttke, T.V.; Helbig, I.; Marini, C.; Johannesen, K.M.; Brilstra, E.H.; Vaher, U.; Borggraefe, I.; Talvik, I.; Talvik, T.; et al. Mutations in GABRB3: From febrile seizures to epileptic encephalopathies. Neurology 2017, 88, 483-492. [CrossRef]

54. Salpietro, V.; Dixon, C.L.; Guo, H.; Bello, O.D.; Vandrovcova, J.; Efthymiou, S.; Maroofian, R.; Heimer, G.; Burglen, L.; Valence, S.; et al. AMPA receptor GluA2 subunit defects are a cause of neurodevelopmental disorders. Nat. Commun. 2019, 10, 3094. [CrossRef]

55. Reijnders, M.R.F.; Janowski, R.; Alvi, M.; Self, J.E.; van Essen, T.J.; Vreeburg, M.; Rouhl, R.P.W.; Stevens, S.J.C.; Stegmann, A.P.A.; Schieving, J.; et al. PURA syndrome: Clinical delineation and genotype-phenotype study in 32 individuals with review of published literature. J. Med. Genet. 2018, 55, 104-113. [CrossRef]

56. Salpietro, V.; Malintan, N.T.; Llano-Rivas, I.; Spaeth, C.G.; Efthymiou, S.; Striano, P.; Vandrovcova, J.; Cutrupi, M.C.; Chimenz, R.; David, E.; et al. Mutations in the Neuronal Vesicular SNARE VAMP2 Affect Synaptic Membrane Fusion and Impair Human Neurodevelopment. Am. J. Hum. Genet. 2019, 104, 721-730. [CrossRef]

57. Straub, J.; Konrad, E.D.H.; Grüner, J.; Toutain, A.; Bok, L.A.; Cho, M.T.; Crawford, H.P.; Dubbs, H.; Douglas, G.; Jobling, R.; et al. Missense Variants in RHOBTB2 Cause a Developmental and Epileptic Encephalopathy in Humans, and Altered Levels Cause Neurological Defects in Drosophila. Am. J. Hum. Genet. 2018, 102, 44-57. [CrossRef] [PubMed]

58. Platzer, K.; Yuan, H.; Schütz, H.; Winschel, A.; Chen, W.; Hu, C.; Kusumoto, H.; Heyne, H.O.; Helbig, K.L.; Tang, S.; et al. GRIN2B encephalopathy: Novel findings on phenotype, variant clustering, functional consequences and treatment aspects. J. Med. Genet. 2017, 54, 460-470. [CrossRef] [PubMed]

59. Zhang, Z.B.; Tian, M.Q.; Gao, K.; Jiang, Y.W.; Wu, Y. De novo KCNMA1 mutations in children with early-onset paroxysmal dyskinesia and developmental delay. Mov. Disord. 2015, 30, 1290-1292. [CrossRef] [PubMed]

60. Zou, F.; McWalter, K.; Schmidt, L.; Decker, A.; Picker, J.D.; Lincoln, S.; Sweetser, D.A.; Briere, L.C.; Harini, C.; Members of the Undiagnosed Diseases Network; et al. Expanding the phenotypic spectrum of GABRG2 variants: A recurrent GABRG2 missense variant associated with a severe phenotype. J. Neurogenet. 2017, 31, 30-36. [CrossRef] [PubMed]

61. Papandreou, A.; Danti, F.R.; Spaull, R.; Leuzzi, V.; Mctague, A.; Kurian, M.A. The expanding spectrum of movement disorders in genetic epilepsies. Dev. Med. Child. Neurol. 2020, 62, 178-191. [CrossRef] [PubMed] 
62. Cellini, E.; Vignoli, A.; Pisano, T.; Falchi, M.; Molinaro, A.; Accorsi, P.; Bontacchio, A.; Pinelli, L.; Giordano, L.; Guerrini, R.; et al. The Hyperkinetic Movement Disorder of FOXG1-related Epileptic-Dyskinetic Encephalopathy. Dev. Med. Child. Neurol. 2016, 58, 93-97. [CrossRef]

63. Spagnoli, C.; Soliani, L.; Caraffi, S.G.; Baga, M.; Rizzi, S.; Salerno, G.G.; Frattini, D.; Garavelli, L.; Koskenvuo, J.; Pisani, F.; et al. Paroxysmal movement disorder with response to carbamazepine in a patient with RHOBTB2 developmental and epileptic encephalopathy. Parkinsonism Relat. Disord. 2020, 76, 54-55. [CrossRef]

64. Wassenberg, T.; Molero-Luis, M.; Jeltsch, K.; Hoffmann, G.F.; Assmann, B.; Blau, N.; Garcia-Cazorla, A.; Artuch, R.; Pons, R.; Pearson, T.S.; et al. Consensus guideline for the diagnosis and treatment of aromatic l-amino acid decarboxylase (AADC) deficiency. Orphanet. J. Rare Dis. 2017, 12, 12. [CrossRef] [PubMed]

65. Graziano, C.; Wischmeijer, A.; Pippucci, T.; Fusco, C.; Diquigiovanni, C.; Nõukas, M.; Sauk, M.; Kurg, A.; Rivieri, F.; Blau, N.; et al. Syndromic intellectual disability: A new phenotype caused by an aromatic amino acid decarboxylase gene (DDC) variant. Gene 2015, 559, 144-148. [CrossRef] [PubMed]

66. Rahman, S. Mitochondrial disease and epilepsy. Dev. Med. Child. Neurol. 2012, 54, 397-406. [CrossRef] [PubMed]

67. Holder, J.L., Jr.; Agadi, S.; Reese, W.; Rehder, C.; Quach, M.M. Infantile spasms and hyperekplexia associated with isolated sulfite oxidase deficiency. JAMA Neurol. 2014, 71, 782-784. [CrossRef]

68. Carecchio, M.; Mencacci, N.E. Emerging monogenic complex hyperkinetic disorders. Curr. Neurol. Neurosci. Rep. $2017,17,97$. [CrossRef]

69. McTague, A.; Howell, K.B.; Cross, J.H.; Kurian, M.A.; Scheffer, I.E. The genetic landscape of the epileptic encephalopathies of infancy and childhood. Lancet Neurol. 2017, 15, 304-316. [CrossRef]

70. Della Sala, G.; Pizzorusso, T. Synaptic plasticity and signaling in Rett syndrome. Dev. Neurobiol. 2014, 74, 178-196. [CrossRef]

71. Nunes, M.L.; Yozawitz, E.G.; Zuberi, S.; Mizrahi, E.M.; Cilio, M.R.; Moshé, S.L.; Plouin, P.; Vanhatalo, S.; Pressler, R.M. Task Force on Neonatal Seizures, ILAE Commission on Classification \& Terminology. Neonatal seizures: Is there a relationship between ictal electroclinical features and etiology? A critical appraisal based on a systematic literature review. Epilepsia Open 2019, 4, 10-29.

72. He, N.; Lin, Z.J.; Wang, J.; Wei, F.; Meng, H.; Liu, X.R.; Chen, Q.; Su, T.; Shi, Y.W.; Yi, Y.H.; et al. Evaluating the pathogenic potential of genes with de novo variants in epileptic encephalopathies. Genet. Med. 2019, 21, 17-27. [CrossRef]

73. Allen, A.S.; Berkovic, S.F.; Cossette, P.; Delanty, N.; Dlugos, D.; Eichler, E.E.; Epstein, M.P.; Glauser, T.; Goldstein, D.B.; Han, Y.; et al. De novo mutations in epileptic encephalopathies. Nature 2013, 501, 217-221.

74. Kryukov, G.V.; Pennacchio, L.A.; Sunyaev, S.R. Most rare missense alleles are deleterious in humans: Implications for complex disease and association studies. Am. J. Hum. Genet. 2007, 80, 727-739. [CrossRef] [PubMed] 